\title{
The Role of Judicial Discretion in Dispute Settlement*
}

\author{
James Andreoni \\ University of California, San Diego \\ Department of Economics
}

\author{
June 2007 \\ Current version February 19, 2008
}

\author{
Ray D. Madoff \\ Boston College \\ Law School
}

\begin{abstract}
We consider two common modes of judicial resolution: judicial discretion, where the judge or jury has broad discretion in fashioning a remedy, and winner take all where the remedy is pre-determined by the governing substantive law. We analyze these systems in light of the fact that pre-trial bargainers have been shown to have excessive confidence in their own positions. We find theoretically that winner-take-all rules magnify the effects of over-confidence and diminish the likelihood of settling relative to judicial discretion. We confirm our model with a laboratory experiment showing significantly fewer pre-trial agreements under winner-take-all. These results imply that increasing judicial discretion in fashioning remedies could increase pre-trial agreements and promote efficiency. This has implications for many areas of law, including donative transfers, property law, patent infringements, and agreements on liquidated damages.
\end{abstract}

*We would like to thank the American College of Trust and Estates Council Foundation, and the National Science Foundation (through grant numbers SES-0320106 and SES-0551296 to Andreoni) for financial support. We are also grateful to Linda Babcock, Honourable Herbert P. Wilkins (Chief Justice, Massachusetts Supreme Judicial Court, retired) and Honourable Edward M. Ginsburg (Massachusetts Probate and Family Court Judge, retired) for their help in formulating our experiment, to Max Bazerman, Vincent Crawford, Stephen Leider, and Muhamet Yildiz for extremely helpful comments, and to Megan Watson and Justin Rao for expert research assistance. 


\section{Introduction}

When parties to a law suit fail to settle, the case will appear before a court. Depending on the substantive law governing the dispute, the decision maker, be it judge or jury, will either have broad discretion in establishing the amount awarded to the prevailing party, or have no discretion in fashioning a remedy because the law imposes a winner-take-all system. Through theory and experiments we show that winner-take-all leads to significantly more bargaining delays and disagreements than cases where the decision maker has broader discretion. Such a finding has important consequences for how we design mechanisms for resolving disputes.

Our analysis is motivated by a puzzling observation from legal scholars. They have noted that when a decedent's will is challenged, these disputes reach out-of-court settlements at a far lower rate than other civil litigation. According to empirical studies, while fewer than $8 \%$ of other civil litigation requires a court to resolve the case (Trubek, et al.1983), 40\% of disputed wills do (Schoenblum, 1987). ${ }^{1}$ What could account for this five-fold difference in rates of disagreement?

In probing this question, Madoff (2002) notes a number of differences between will disputes and other litigation. The claims in a contested will or other donative transfer often center on questions about the true intent of a person who is no longer living, and often have strong emotional or moral components. Each of these could affect parties willingness to settle. Another distinguishing factor of these types of disputes, and the one that we explore in this paper, is the fact that judges lack discretion in fashioning remedies for disputes involving donative transfers (transfers by gift and at death). If a will or gift is challenged, a judge resolving that dispute can only either uphold or reject the transfer. A judge does not

\footnotetext{
${ }^{1}$ Objective evidence on this is difficult to collect, as court records on will disputes are maintained in local probate courts. These courts typically do not have funding that would allow them to aid in research, and, additionally, often maintain records in ways that make them difficult to study. Despite these obstacles, Schoenblum (1987) examined nine years of probate records for a single county and found $38 \%$ were resolved through out-of-court settlements and $22 \%$ were dismissed either voluntarily or involuntarily. The rest, $40 \%$, were resolved through a trial. There is also subjective evidence gained though interviews with probate attorneys and judges that corroborate these statistics. See Madoff (2002) for a detailed discussion of this evidence.
} 
have any equitable authority to fashion a remedy particular to the situation - the judgement is winner-take-all. This is unlike many other civil disputes where the judicial decision-maker has far greater discretion in determining awards. For example, in torts cases, the issue of damages is highly fact-sensitive and is subject to varying assessments of value, particularly for non-economic damages such as pain and suffering. Likewise, in contract cases there are a variety of standards that a judge can use in assessing damages that can result in the prevailing parties receiving widely varying amounts. The winner-take-all aspect of wills law in the United States is also unlike wills law in other common law countries, including England, Australia and New Zealand, where judges have equitable powers to alter the plan of disposition under an otherwise valid will.

How could the winner-take-all doctrine affect settlement? Since winner-take-all obviously increases the risk faced by litigants, one might predict that agreements would be more frequent under winner-take-all than judicial discretion. Since this contradicts the facts, risk aversion cannot explain the difference we observe.

Overconfidence is perhaps the most common and well-established reason for a failure to reach agreement through negotiation. ${ }^{2}$ The natural question is, therefore, does winner-takeall somehow heighten the negative consequences of overconfidence? Our hypothesis is that it does and that this effect is likely to be responsible for the empirical finding of greater rates of disagreement under winner-take-all. Intuitively, an overconfident bargainer assigns unrealistically high likelihood to "winning" and thus believes the expected benefits of going to court are higher than they actually are. Relative to judicial discretion, winner-takeall concentrates the payments of winning on the most extreme outcomes possible, thereby increasing a biased litigant's expected returns from going to court. That is, litigants who may have agreed under judicial discretion could find the contract zone is empty if they switch to winner-take-all. ${ }^{3}$ We formalize this intuition in a theoretical model.

\footnotetext{
${ }^{2}$ Babcock and Loewenstein (1997) provide a nice summary of the experimental literature. See Yildiz (2004) for a recent theoretical contribution. We review this literature in section 2 below.

${ }^{3}$ Another way of thinking of this issue is that judicial discretion serves to temper the self-serving bias in that someone who thinks they have a winning case will nonetheless recognize that they cannot know how a
} 
The laboratory test of our theory asks subjects to assume the roles of litigants in a disputed will and donative transfer. Litigants negotiate in a computer "chatroom" format. There are two conditions, reflecting either winner-take-all or judicial discretion. As predicted, subjects in both conditions exhibit similar degrees of overconfidence, but have a significantly greater likelihood of disagreement under winner-take-all.

Although our discussion is in terms of wills law, our hypothesis also applies broadly to circumstances where, by law or by contract, the institution limits the discretion of a judge or other decision maker in fashioning a remedy. One area where this applies is private contracts that include fixed penalties for breach, called "liquidated damages." These clauses may have the effect of making recontracting more difficult if the parties suffer from overconfidence, resulting in lower efficiency. Moreover, most property cases involving contested ownership, such as disputed property lines, abandoned property, and squatters' rights, are subject to winner-take-all rules. Our theory is particularly relevant to remedies in patent disputes and the recent Supreme Court case on this issue in connection with the "buy now" button used by the Internet company eBay. We treat this case this in more detail in our discussion. Our general claim is that granting greater discretion to a judge or decision maker in the event of a disagreement is likely to increase the propensity of overconfident litigants to settle the case, thus increasing economic efficiency.

In the next section we provide more detail on wills, legal doctrine, and overconfidence. Section 3 presents the theoretical model. Section 4 describes our experimental design, and section 5 provides the results. In section 6 we summarize our findings and discuss their consequences for the law and for behavioral issues in economics.

judge or jury will exercise discretion. 


\section{Background}

\subsection{Law of Donative Transfers}

Under American law, unmarried individuals are free to dispose of their property as they see fit. ${ }^{4}$ This is unlike the law in most other parts of the world, which requires that an individual share a portion of his or her estate with children and other relatives. ${ }^{5}$ This right to transmit property can be exercised during life, through lifetime gifts, or at death through a will. The only limitations on this right are, first, that the transfer must conform with the legal formalities required for the transfer (for instance, if it is a will, it must be signed in the presence of two witnesses who also sign the will, and if it is a gift, there must be delivery and acceptance of the property); and second, the person making the transfer must have the requisite intent to make the transfer. ${ }^{6}$ A person lacks the requisite mental intent when he is under undue influence. A person is considered to be under undue influence when he is subject to another person's exertion of control such that he takes actions which are different from his true wishes.

If a person makes a transfer that meets the formal requirements and has sufficient mental capacity, then the transfer is effective. If a person makes a transfer that fails to meet the formal requirements or the person lacks the requisite mental capacity, then the transfer is not effective. A judge's authority in a donative transfer case is limited to either upholding or negating the transfer. A judge does not have the right to exercise discretion in fashioning a remedy. This is unlike the law of many other common law countries, in which a court has broad discretionary rights to make a "fair" disposition of a decedent's estate. Nor is it like

\footnotetext{
${ }^{4}$ Depending on the state, married individuals may be required to transfer a portion of their property to their spouse. See Ray D. Madoff, Cornelia R. Tenney and Martin A. Hall, Practical Guide to Estate Planning $\S 6.02(2008)$.

${ }^{5}$ Most civil law systems provide for a form of forced heirship in which children and other relatives are entitled to a portion of the decedent's estate (De Waal, 2006). Our closest legal relatives, the common law countries of England, Australia, New Zealand, as well as some provinces of Canada, have enacted Family Maintenance Statutes that allow a judge to alter the disposition of a person's property for the benefit of family members. For a discussion of this issue, and related references, see Madoff (2002).

${ }^{6}$ This is called "donative intent" for gifts and "testamentary intent" for wills.
} 
other civil suits where judges have a great deal of discretion in awarding a remedy.

\subsection{Evidence of Overconfidence in Bargaining}

Overconfidence, excessive optimism, self-serving bias, and non-common priors are terms used in the literature to represent the idea that an individual has unrealistically favorable expectations for the consequences of disagreement.

The evidence for overconfidence is extremely strong, and is spelled out nicely in a review by Babcock and Loewenstein (1997). They catalogue an extensive psychology literature that shows that people have a basic tendency towards self-serving interpretations, especially when there are several possible "focal points" for what could be seen as fair or reasonable. Babcock and Loewenstein then discuss an important series of papers by themselves and coauthors (most notably Babcock, Wang and Loewenstein, 1996, and Babcock, Loewentein, Isacharoff, and Camerer, 1995) that show the persistence of self-serving bias in experimental settings. A typical experiment asked subjects, who were students from university courses, to play the roles of litigants. Roles as plaintiff and defendant were assigned randomly. Subjects were given identical case materials to review and, before negotiating, were asked for their best guess of the judge's ruling on damages in the event the case goes to court. Subjects then had a set amount of time to negotiate, and if they failed to reach agreement in this time they would go to court and receive the judge's ruling. The authors found that the plaintiffs consistently estimated the judge's ruling to be higher than the defendants' estimates, indicating a significant self-serving bias. Moreover, this bias was a significant predictor of disagreement in pre-trial bargaining. In fact, Babcock, Loewenstein and Wang (1995) show that the self-serving biases can cause the contract zone the set of possible agreements that make both sides better off than they expect to be by going to court- to disappear. 


\subsection{Comparison to Arbitration in Contract Negotiations}

Judicial discretion and winner-take-all each bear some resemblance to dispute resolution mechanisms often discussed in the literature on contract negotiations, namely conventional arbitration and final offer arbitration. Conventional arbitration is similar to judicial discretion in that the arbitrator typically has broad discretion in his choice of remedy. Final offer arbitration (FOA), on the other hand, limits the discretion of the arbitrator in that each party submits a proposed settlement amount to the arbitrator, who then must choose one of the two offers submitted. Evidence from both the laboratory and the field show that parties are more likely to settle prior to a decision being rendered when they participate in FOA as opposed to conventional arbitration (see, for example, Neale and Bazerman, 1983, Ashenfelter, Curie, Farber, and Spiegel, 1992, and Dickinson, 2004).

At first glance, the literature on FOA seems to contradict our findings because conventional arbitration resembles judicial discretion, and FOA appears similar to winner-take all, yet FOA results in more settlements than conventional arbitration. However, there is an important distinction between FOA and the all-or-nothing judicial mechanism that we are studying. Namely, in FOA, the potential remedies are determined by the bargainers themselves. This gives each side an incentive to make final offers that are closer to the preferences of the arbitrator in hopes of being chosen over the final offer of their opponent, thus bringing the two sides together (Farber and Bazerman, 1986). This suggests that the increased settlement rates in FOA is prompted by something other than the limited discretion by the decision-maker. This makes the findings of the increased efficiency of FOA largely inapposite to our situation.

There is one aspect of the FOA literature however that is relevant That is, Dickinson (2006) has shown that even in FOA, the effect of self-serving optimism is to attenuate the benefits of FOA and, with extreme enough optimism, can even cause FOA to fail. 


\subsection{Theories of Overconfidence in Bargaining}

Excessive optimism has also been at the root of several theoretical models of disagreement in bargaining, such as Landes (1971) and Posner (1972) who show optimism can cause disagreement. Recently, Muhamet Yildiz has produced an interesting series of papers showing that under certain conditions optimism in bargaining may not lead to delay or disagreement. He assumes bargainers have opportunities to make proposals at randomly determined times, and individuals may be optimistic about when they will next get a chance to make an offer. In Yildiz (2003), he shows that if the bargaining horizon is short, this optimism can lead to disagreement - the contract zone can be an empty set. If the horizon is sufficiently long, however, and people remain sufficiently optimistic then immediate agreement may be possible. Loosely speaking, if there will be many opportunities to make offers over an extended period, discounting by bargainers can cause the contract zone to "open up." In Yildiz (2004), he broadens the model to include learning and shows that once again optimism can cause delay in agreement, but only as it interacts with learning and if people are sufficiently patient. As Yildiz concedes, however, he cannot deny the importance of optimism in disagreement and delay in bargaining, but instead sees his papers a "first step towards a more careful analysis of optimism and the important role it plays in negotiation" (2003, p.796).

The model of bargaining that comes closest to capturing the effects we are discussing here is by Olszewski (2006), who explores the welfare differences between conventional arbitration and final-offer arbitration. In one of the models he presents, he assumes bargainers have different self-serving priors about what the arbitrator will decide. Furthermore, each party believes that their opponent is biased, that they themselves are not biased, and that the arbitrator shares their own point of view. While each bargainer believes the arbitrator is unbiased, the arbitrator's decision is still taken to be uncertain. In particular, there is an unbiased error in the arbitrator's belief about which bargainer's position is "correct." He shows that in final-offer arbitration the bargainers will "exaggerate" their final offers in equilibrium in order to take advantage of the perceived bias of their opponent. The only 
thing that keeps them from stating infinite offers is that the potential error on the part of the arbitrator. Unfortunately for our purposes, Olszewski makes the simplifying assumption that imply overconfidence is essentially a binary variable - bargainers either see the facts clearly (and thus agree) or one or both maintain a bias and both are perfectly (although perhaps erroneously) convinced of their positions and believe equally strongly that the arbitrator will agree with them. In addition, he assumes that the arbitrator either sides perfectly with one of the negotiators or is indifferent. These assumptions makes agreement insensitive to increases in subjective expected returns from disagreement. If we replace Olszewski's informational assumptions with assumptions similar to those we make in the next section, his approach will likely lead to the conclusions we propose next.

\section{Theoretical Analysis}

This section presents theoretical analysis in support of our hypothesis. Our objective is not to present a full blown model of bargaining, but simply take the first step needed to solve any bargaining model, which is to identify the contract zone. The contract zone is the set of possible agreements that would leave both players at least as well off as they expect to be by going to court. The objective is to show that a winner-take-all judicial doctrine, in the presence of optimism, can cause the contract zone to shrink or disappear relative to the case of judicial discretion. A motivation for this approach can be drawn from the industrial relations literature which typically measures the probability of reaching a settlement without intervention of a court or other arbitrator by the size of the contract zone (see, for instance, Farber, 1980, and Farber and Bazerman, 1986). Given that we establish the starting position for negotiation, researchers can then apply their favorite models of bargaining to generate predictions about agreement, such as a modification of the model of Olszewski (2006) noted above.

While there is intuitive appeal to the notion that a smaller contract zone means greater likelihood of delay or disagreement, one should be careful to note that for most theoretical 
approaches simply showing a smaller contract zone does not necessarily translate into longer delay or greater likelihood of disagreement (Crawford, 1979, 1981). Many standard models of negotiation, for instance, predict agreement as long as the contract zone is not empty. In applying these models, however, one would only need to acknowledge that our approach shows that the contract zone is more likely to be empty under winner-take-all to generate the desired prediction. At the end of this section we provide a simple numerical example to show how the contract zone can be much more likely to be empty under winner-take-all than under greater judicial discretion.

The theory we present can be interpreted as providing a foundation for a model of bargaining with two-sided incomplete information. It has been shown that in such cases that agreement is not assured, even when the contract zone is non-empty, and that the likelihood of agreement is increasing in the size of the contract zone (Myerson and Satterthwaite, 1983, and Ausebel, Cramton, and Deneckere, 2002).

\subsection{Setup}

Assume two individuals, $A$ and $B$, are litigants. Normalize the claims and court costs such that Person $A$ claims that he is owed $\$ 1$ that is currently held by $B$. If $A$ and $B$ fail to reach a negotiated settlement, the case will go to court. Let $p$ represent the court's view of the probability that $A$ 's claim as valid. A stronger case by $A$ yields a higher $p$. Let $x$ be the final award that the court gives to $A$. Then we will make the following assumptions about how, upon forming $p$, the court must rule under the two doctrines:

Winner-take-all: If $p>1 / 2$ the judge must rule in favor of $A$, choosing $x=1$, otherwise $x=0$.

Judicial Discretion: The award will be proportional to the probability that $A$ 's case is valid, so $x=p$.

Assume a litigant views $p$ as a random variable with a probability distribution function $f(p), 0 \leq p \leq 1$. Let $\bar{p}$ be the expected value of $p$. 
Assume there are no costs to negotiation, but that a court hearing will $\operatorname{cost} c_{i}$, where $0 \leq c_{i} \leq 1, i=A, B$, and $c_{A}+c_{B}<1$. Costs are assumed to be the same under both doctrines. $^{7}$

We make two more assumptions about individuals. First, we make the standard assumption that litigants are risk neutral. We discuss the consequences of adding risk aversion later in the paper, but, as already noted, risk aversion will work against our hypothesis. Second, we assume that if individuals are overconfident then they are unaware of their own bias or their own potential to be biased, and that overconfidence is not the result of strategic play. This is consistent with the laboratory research - if subjects see a breakdown in negotiations, they tend to assume the other party is biased, but not themselves (Babcock and Loewenstein, 1997).

\subsection{Litigants Have Common Beliefs}

Here we show that if there is no overconfidence then winner-take-all and judicial discretion doctrines yield contract zones of identical size. Specifically, we assume litigants share common beliefs on the distribution of potential decisions by the court. ${ }^{8}$

First consider the doctrine of judicial discretion. For $A$ the expected outcome of the trial is $\bar{p}$ and thus the expected value of going to court is $v_{A}=\bar{p}-c_{A}$. Likewise, for $B$ the expected value is $v_{B}=1-\bar{p}-c_{B}$. Let $s$ be the settlement that $B$ agrees to pay to $A$. Any $s \in\left[\bar{p}-c_{A}, \bar{p}+c_{B}\right]$ will make both $A$ and $B$ at least as well of as going to court. This is the contract zone - as long as there are extra costs in going to court, we would always predict agreement is possible.

Now consider winner-take-all. Let $\theta=\int_{1 / 2}^{1} f(p) d p$ be the the probability that $p>1 / 2$. For $A$ the expected outcome of the trial is $\theta$ and thus the expected value of going to court is $v_{A}=\theta-c_{A}$. Likewise, for $B$ the expected value is $v_{B}=1-\theta-c_{B}$. The contract zone is now any $s \in\left[\theta-c_{A}, \theta+c_{B}\right]$.

\footnotetext{
${ }^{7}$ Note, both the pie and the costs have been scaled by the same factor.

${ }^{8}$ The results of this subsection can be derived under some special cases of disparate beliefs. Since there is nothing inherently interesting about these special cases, we assume common beliefs for simplicity.
} 
In both of these cases, the width of the contract zone is $c_{A}+c_{B}$. It follows that typical models of bargaining would proceed to predict that outcome will be the same under both doctrines. ${ }^{9}$

\subsection{Overconfident Litigants}

The literature has defined overconfidence to mean litigants have either self-serving expectations of the judge's award, or having excessive confidence of "winning" in court relative to the true probability. What matters for our analysis, however, is simply that the litigants have a "bias" relative to each other. In particular, this means $A$ sees those values of $p>1 / 2$ to be as at least as likely as $B$ sees them to bo, while those values of $p \leq 1 / 2$ are seen as no more likely to $A$ than to $B{ }^{10}$

Let $\alpha(p)$ be the $p . d . f$. perceived by $A$, and $\beta(p)$ be the $p . d . f$. perceived by $B$. Then we assume $\alpha(p)$ and $\beta(p)$ satisfy these three conditions: i) $0 \leq \alpha(p) \leq \beta(p)$ for $0 \leq p \leq 1 / 2$, ii) $\beta(p) \leq \alpha(p)$ for $1 / 2<p \leq 1$, and iii) $\int_{0}^{1} \alpha(p) d p=\int_{0}^{1} \beta(p) d p=1$. Another way to state these conditions is that $\alpha(p)$ first-order stochastically dominates $\beta(p)$ with a crossing of the p.d.f.s at $p=1 / 2$. If these conditions are satisfied, then we can say that $A$ and $B$ are overconfident relative to each other. ${ }^{11}$ Note the generality of this definition in that it does not depend on the true p.d.f., but just the relative beliefs of the two litigants.

Begin again with judicial discretion. We know that expected value of $p$ by $A, \bar{p}_{A}$, will be higher than the expected value of $B, \bar{p}_{B}$, that is $\bar{p}_{A}=\int_{0}^{1} p \alpha(p) d p \geq \int_{0}^{1} p \beta(p) d p=\bar{p}_{B}$. The contract zone is now $\left[\bar{p}_{A}-c_{A}, \bar{p}_{B}+c_{B}\right]$. However, since $\bar{p}_{B} \leq \bar{p}_{A}$, this contract zone is

\footnotetext{
${ }^{9}$ See, for instance, Crawford's (1979) comparison of convention and final offer arbitration for a related result. Obviously, this only holds for risk neutral bargainers.

${ }^{10} \mathrm{As}$ in the last subsection, this assumption is stricter than is necessary since the results would also hold under a broader set of disparate beliefs than permitted by this definition. Again, since there is nothing inherently interesting about these special cases, we use this definition of bias because it is most natural and provides for simplicity.

${ }^{11}$ Obviously, these assumptions are only sufficient conditions for our result. If $\alpha(p)$ and $\beta(p)$ deviate modestly from these conditions, our predictions will still hold. However, there appears to be no general characterization of types of deviations that would be allowed, but rather would depend on the full shape of the $\alpha(p)-\beta(p)$. As will be seen in our proof and numerical example, there is likely be a great degree of tolerance for deviations from these three assumptions in our prediction.
} 
shrinking relative to the unbiased case. If the biases are so severe that $\bar{p}_{A}-c_{A}>\bar{p}_{B}+c_{B}$ then the contract zone disappears and no negotiated settlement is possible.

What about winner-take-all? Let $\theta_{A}=\int_{1 / 2}^{1} \alpha(p) d p$ be $A$ 's belief on the probability of winning. Likewise, let $\theta_{B}=\int_{1 / 2}^{1} \beta(p) d p$ be $B$ 's belief of the probability of losing. As before, our assumptions imply that $\theta_{B} \leq \theta_{A}$. The new contract zone is $\left[\theta_{A}-c_{A}, \theta_{B}+c_{B}\right]$, which is clearly smaller than the unbiased zone. Again, if the biases are so big that $\theta_{A}-c_{A}>\theta_{B}+c_{B}$ then no agreements are possible.

\subsection{Overconfidence and Judicial Doctrine}

Our claim here is that under winner-take-all the same biases will lead to a larger reduction in - and more likely elimination of - the contract zone than under judicial discretion. With our theoretical framework, this reduces to a claim that $\bar{p}_{A}-\bar{p}_{B} \leq \theta_{A}-\theta_{B}$. This is simple to demonstrate:

$$
\begin{aligned}
\bar{p}_{A}-\bar{p}_{B} & =\int_{0}^{1 / 2} p(\alpha(p)-\beta(p)) d p+\int_{1 / 2}^{1} p(\alpha(p)-\beta(p)) d p \\
& \leq \int_{1 / 2}^{1} p(\alpha(p)-\beta(p)) d p \\
& \leq \int_{1 / 2}^{1}(\alpha(p)-\beta(p)) d p \\
& =\theta_{A}-\theta_{B} .
\end{aligned}
$$

The first step follows from the assumption that $\alpha(p) \leq \beta(p)$ for $p \leq 1 / 2$, while the second step follows from the assumption that $\alpha(p) \geq \beta(p)$ for $p>1 / 2$.

This indicates not only that the contract zone shrinks with overconfidence, but that it shrinks more under winner-take-all. Intuitively, winner-take-all concentrates the bias on the most favorable outcome of winning it all, and, in effect, magnifies the over-estimation of an expected court decision. Thus, agreements that would have been possible under judicial discretion are no longer feasible for winner-take-all. In fact, cases may arise in which agreement is possible for judicial discretion but impossible for winner-take-all. ${ }^{12}$

\footnotetext{
${ }^{12}$ Looking at the mathematics above, it is easy to see how exceptions to assumptions $(i)$ and $(i i)$ can be
} 


\subsection{Example}

To illustrate this finding, suppose an unbiased litigant would believe that $p$ is distributed uniformly, so $f(p)=1,0 \leq p \leq 1$. Then $\bar{p}=\theta=1 / 2$.

Assume that $A$ 's belief about this distribution is biased. In particular, assume $\alpha(p)=$ $1-a$, for $0 \leq p \leq 1 / 2$ and $\alpha(p)=1+a$ for $1 / 2<p \leq 1$. Similarly, assume $B$ 's beliefs are $\beta(p)=1+b$ for $0<p \leq 1 / 2$ and $\beta(p)=1-b$ for $1 / 2 \leq p \leq 1$. Of course, $0<a, b<1$.

$>$ From these it is easy to calculate $\bar{p}_{A}=\int_{0}^{1 / 2} p(1-a) d p+\int_{1 / 2}^{1} p(1+a) d p=(1-a) / 8+$ $3(1+a) / 8=1 / 2+a / 4$. Similarly, $\bar{p}_{B}=1 / 2-b / 4$. The contract zone under the doctrine of judicial discretion is $s \in\left[1 / 2+a / 4-c_{A}, 1 / 2-b / 4+c_{B}\right]$. If $(a+b) / 4>c_{A}+c_{B}$ the contract zone will disappear.

Turning to winner-take-all, we find $\theta_{A}=\int_{1 / 2}^{1}(1+a) d p=1 / 2+a / 2$. Likewise, $\theta_{B}=$ $1 / 2-b / 2$. Now the contract zone becomes $s \in\left[1 / 2+\alpha / 2-c_{A}, 1 / 2-b / 2+c_{B}\right]$. This is clearly a smaller contract zone. Moreover, if $(a+b) / 2>c_{A}+c_{B}$ then the contract zone vanishes and no agreement is possible. Hence, for a given set of biases, disagreement and delay is far more likely under winner-take-all.

To illustrate this with numbers, suppose that each side believes their chance of the judge finding their case is valid is $60 \%$, rather than the unbiased $50 \%$, that is, $\theta_{A}=1-\theta_{B}=0.6$. It is easy to see that this means $a=b=0.2$. Thus, in the case of judicial discretion, there can be agreements only if $0.1 \leq c_{A}+c_{B}$, that is, if total litigation costs exceed $10 \%$ of the value of the stakes being bargained over. Turning to winner-take-all, there can only be agreement if $0.2 \leq c_{A}+c_{B}$, that is, if total litigation costs exceed $20 \%$ of the stakes. As can be seen in this example, rather slight overconfidence can lead to much greater hazard of disagreement under winner-take-all.

handled, and that each deviation will need to be considered as a special case. Nonetheless, the slack left when applying each inequality would seem to imply that many modest deviations would leave the implications intact. 


\section{Experimental Design}

As in prior studies of pre-trial bargaining, our experiment asks student volunteers to assume the roles of two people in a disputed will. This section will first describe the scenario and the manipulation we use to test our hypotheses, then present the specific details of how the design was implemented.

\subsection{Bargaining Scenarios and Manipulation}

We constructed a situation, loosely based on a real case, in which a brother and sister are in disagreement about $\$ 800,000$ in their mother's estate. In the scenario, the sister, a struggling artist and a single parent, had recently moved from New York to live with her elderly mother. While she was able to live rent-free, the move arguably also derailed her chances of being a successful artist. The brother, in the mean time, was a single man living in Washington pursuing a highly successful and lucrative career as an attorney. Busy with his career, he rarely visited his mother. Near the end, the mother had become ill, was often confused, and became increasingly dependant on her daughter to make decisions for her.

For years the mother's will had stipulated that the estate should be divided evenly between her children. However, three months prior to her death, the sister drove her mother to the bank where the mother withdrew $\$ 800,000$ from her own account and deposited it in the account of the sister, thus removing the money from the estate and reducing the brother's inheritance by $\$ 400,000$.

The brother's claim is that the mother's true wish was to divide her estate evenly as specified in her will and that the $\$ 800,000$ gift was the result of the sister's exertion of undue influence on the mother. He is asking that the gift be set aside, in which case it would pass by the will and he would receive his $50 \%$ share of the $\$ 800,000$, that is, $\$ 400,000$. The sister's claim, by contrast, is that mother fully intended to make the gift and she made it out of appreciation for the personal and career sacrifices that the sister had made. She claims the full $\$ 800,000$ is rightfully hers. At stake, therefore, is $\$ 400,000$. 
The instructions state that the brother is seeking to set aside the gift under the doctrine of undue influence, and give a clear definition of the doctrine and the standards that apply.

There are then two possible conditions. Under the winner-take-all condition, we explain that the judge will find for either the sister or the brother. We explain the judges' options to the brother this way:

If the judge finds that the transfer was the product of undue influence, then you will receive the entire $\$ 400,000$ in dispute and your sister will receive nothing. If the judge finds that the transfer was not the product of undue influence, then you will receive nothing, and your sister will receive the $\$ 400,000$ in dispute.

There is a parallel representation to the sister.

Under the judicial discretion condition we replace the paragraph above with this wording for both the brother and sister:

The judge will consider all of the facts and circumstances and will make a fair and equitable distribution of the $\$ 400,000$ in dispute. This will result in you being paid somewhere between $\$ 0$ and $\$ 400,000$.

Other than these two paragraphs, the instructions and case materials are identical under the two conditions.

\subsection{Implementation}

The subjects were volunteers from undergraduate courses at the University of Wisconsin in November, 2005. Each session of the experiment required 20 subjects. As subjects arrived they were randomly assigned a subject number and role in the study. All those in the role

of the brother (role $\mathrm{A}$ in the experiment) were on one side of the room, and those in the role of the sister (role B) were on the other side, and the two were separated by a room divider. However, both sides could see the experimenter and see the projection screen at the front of the room. Thus, everyone was able to verify that both roles had the same instructions, 
but no two negotiators could ever discover which of the 10 participants of the other role was their partner. We ran two sessions of each condition for a total of 80 subjects. Each session was completed in about one hour.

Subjects were first told that they had earned a $\$ 12$ "participation fee." After explaining the bargaining task, they were told that they would earn an additional $\$ 3$ for every $\$ 100,000$ they were awarded as a result of either negotiation or a judge's court order. If they went to court, however, they would each pay $\$ 10,000$ in attorney's fees. For instance, if they were to negotiate an even split of the $\$ 400,000$ they would each get $\$ 18$. However if one side were to win everything in court, the winner would get $\$ 23.70$ and the loser would get $\$ 11.70$.

Subjects negotiated for settlement over a computer "chatroom." The user interface was deliberately designed with the "look and feel" of standard Internet chatrooms with which college students are familiar. After reviewing the instructions aloud with subjects, they were given 15 minutes to silently review their case materials and prepare for the negotiation. They were then given 15 minutes in which to negotiate. A clock on their chatroom screen counted down the time, and flashed red when one minute remained. To propose a settlement, a subject used a window in the chatroom program to formally send a proposal. Proposals and counter-proposals could be sent and revised at any time. An agreement was reached when one subject accepted the other's proposal. This was done by clicking the button marked "Accept Proposal." If they failed to reach an agreement in the allotted time, the case would "go to court" and they would receive an amount determined by the judge. Only those subjects who failed to reach agreement learned the judge's decision.

How did we determine the outcome of going to court? As indicated in the instructions to the subjects, we asked a state judge to read the case materials seen by the subjects and to make a decision. The judge, who also serves on the faculty at Boston College Law School, ruled in favor of the sister under winner-take-all, but awarded $\$ 50,000$ to the brother under judicial discretion.

Before beginning negotiations, subjects were asked four questions intended to measure 
overconfidence. Subjects were asked 1) their best estimate about what would happen if they were to go to court, 2) how confident they were in their answer to this question, 3) whether they thought there truly was undue influence (rated on a five point scale), and 4) what they thought was a fair division of the $\$ 400,000$. Ideally, we hoped to find that subjects in the two conditions had equal amounts of overconfidence, that is, we wanted to be sure that the treatment variable is only acting on disagreement and not the degree of overconfidence. Notice that since the possible court outcomes are, by design, different across conditions, the answer to question (1) would not be directly comparable in measuring overconfidence. Instead, we used their belief about what is most fair allocation (question 4), and their beliefs about whether undue influence had occurred (question 3) as measures of overconfidence. The answers to questions 3 and 4 were, however, highly correlated with their predictions of the court's decision.

After negotiating and learning the outcome, subjects were given a follow up questionnaire asking them, among other things, to write a definition of "undue influence." All subjects were able to describe this concept accurately. Copies of the instructions, questionnaire, case materials, user interface, and two sample transcripts are presented in the appendix. Transcripts of all the negotiations are available from the authors.

\section{Results}

There were 20 pairs of bargainers under winner-take-all and 20 pairs under judicial discretion. Our prediction was that we should have more disagreement and fewer settlements in winnertake-all. As shown in Table 1, this was exactly what we found. Fifty percent of bargainers agreed under judicial discretion, but only $25 \%$ agreed under winner-take all. Using a simple $t$-test, this difference is significant beyond the $1 \%$ level $(t=2.39)$. There was also evidence

of more delay under winner-take-all. Measuring the time remaining in the bargaining period at agreement for just those pairs who ultimately agreed, a Mann-Whitney test showed 
significant less time remaining for winner-take-all than for judicial discretion $(z=-4.76) .{ }^{13}$ What about the allocation in agreement? Our theory makes no prediction on this, and the data reveal no systematic differences: the Mann-Whitney $z=0.61$.

TABLE 1

Agreements: Allocation to the Brother And Time Remaining in Bargaining Period

\begin{tabular}{|c|c|c|c|}
\hline \multicolumn{2}{|c|}{ Winner-Take-All } & \multicolumn{2}{|c|}{ Judicial Discretion } \\
\hline Amount & Time Left & Amount & Time Left \\
\hline 200 & $10: 19$ & 200 & $12: 41$ \\
\hline 350 & $9: 28$ & 200 & $12: 27$ \\
\hline 250 & $1: 35$ & 200 & $8: 42$ \\
\hline 225 & $0: 18$ & 200 & $4: 46$ \\
\hline 150 & $0: 10$ & 260 & $2: 23$ \\
\hline & & 300 & $1: 49$ \\
\hline & & 200 & $1: 43$ \\
\hline & & 175 & $1: 35$ \\
\hline & & 200 & $0: 32$ \\
\hline & & 200 & $0: 27$ \\
\hline
\end{tabular}

The rest of this section will attempt to tie these results more clearly to the hypothesis of the paper, that winner-take-all is magnifying the effect of overconfidence to create more delay and disagreement.

\subsection{Overconfidence}

To establish that the premises for our theory are met, we need to demonstrate that the subjects were indeed overconfident and that the degree of overconfidence was the same across the conditions. Table 2 confirms this. The table shows the answers to the pre-negotiations questions for both player roles and judicial doctrines. Look first at question 1, where we asked subjects to state the most likely outcome in court. To make the answers comparable across treatments, we code an answer of 200 or more for brother under judicial discretion as the same as saying that the brother wins under winner-take all. The $\chi^{2}$ tests show that players of the two roles are significantly different on their answers, indicating significant

\footnotetext{
${ }^{13}$ An unconditional test of all bargaining pairs, where time remaining equals 0 for disagreement, also shows a signifcant increase in delay under winner-take-all. The Mann-Whitney $z=-8.55$.
} 
overconfidence, but comparing across conditions finds no significant difference. Question 2 shows that subjects of both roles are fairly confident of there forecasts in question 1, with no significant differences in confidence either between roles or between treatments. Question 3 shows that the brother is significantly more likely than the sister to believe that undue influence occurred. ${ }^{14}$ Question 4 shows that each side feels a distribution in their favor is most fair, again with a statistically significant difference. Neither question 3 nor 4, however, show differences between winner-take-all and judicial discretion. Any effects of the treatment, therefore, will be pure treatment effects and not due to any interaction between the treatment and overconfidence.

TABLE 2

Average Responses to the Pre-negotiation Questions and $\chi^{2}$ Tests for Differences For Both Player roles and Winner-take-all (WTA) and Judicial Discretion (JD) Conditions

Player Roles $\chi^{2}$

\begin{tabular}{|c|c|c|c|c|c|c|c|}
\hline & \multicolumn{4}{|c|}{ Player Koles } & \multirow[b]{3}{*}{$A$ vs. $B^{\dagger}$} & \multirow{2}{*}{\multicolumn{2}{|c|}{ WTA vs. JD }} \\
\hline & \multicolumn{2}{|c|}{ A: Brother } & \multicolumn{2}{|c|}{$B:$ Sister } & & & \\
\hline & $W T A$ & $J D$ & $W T A$ & $J D$ & & $A$ & $B$ \\
\hline 1. Guess of judge's allocation to $A$. & 280 & 245 & 100 & 104 & & & \\
\hline Number greater than 200 & 14 & 11 & 5 & 1 & 17.1 & 0.1 & 0.0 \\
\hline $\begin{array}{l}\text { 2. Confidence in answer to } 1 . \\
\begin{array}{l}1=\text { great deal, } 2=\text { some, } \\
3=\text { hardly any }\end{array}\end{array}$ & 2.00 & 2.05 & 1.75 & 1.70 & 4.7 & 0.3 & 0.2 \\
\hline $\begin{array}{l}\text { 3. Was there was undue influence? } \\
1 \text { to } 5 \text { scale: } 1=\text { Yes, definitely } \\
\text { to } 5=\mathrm{No} \text {, definitely }\end{array}$ & 2.00 & 1.90 & 2.95 & 3.50 & 27.8 & 0.3 & 3.3 \\
\hline 4. Most fair allocation to $A$. & 318 & 318 & 115 & 109 & 52.4 & 0.2 & 1.1 \\
\hline
\end{tabular}

$\dagger$ The degrees of freedom for the four $\chi^{2}$ tests are 1,2,4 and 2 respectively. To test 4 , data was grouped into three categories, 0-199, 200, 201-400. Values of $\chi^{2}$ in bold show differences significant beyond the 0.01 level.

\subsection{Disagreement, Delay and Judicial Doctrine}

Next we ask whether, for a given level of overconfidence, the judicial doctrine causes disagreement or delay in bargaining.

\footnotetext{
${ }^{14}$ The range of answers for the daughter was 1 to 3 . That is, no daughter felt there was undue influence. For the sons, however, the range was 2 to 5 . Nine out of 40 answered 2 "no, probably" while the rest answered "maybe, not sure," "yes, probably," or "yes, definitely."
} 
Table 3 reports the marginal effect from Probit regressions, where the dependent variable equals 1 if the bargainers reach an out-of-court settlement. Regression (1) is simply a baseline regression taking no account of the level of overconfidence. We see winner-take-all results in an increase in disagreement by 25 percentage points. Regressions (2) through (6) explore different ways to account for the confidence of the bargainers. The first variable, Difference in Fairness, is simply the brother's answer to pre-question 4 minus the sister's answer, expressed in $\$ 100,000$ 's. The second variable, Difference in Undue Influence, is the brother's answer to pre-question 3 minus the sister's answer. This variable can range from 4 to -4 , although in our sample the range was 4 to -1 . Finally, Disagree on Undue Influence converts the answers to pre-question 3 to a binary variable equal to 1 if the brother answered "Yes, Definitely," "Yes, Probably", or "Maybe, Not Sure" while the sister answered "No, Probably," or "No, Definitely." It also equals 1 if the brother answered "Yes, Definitely," or "Yes, Probably", while the sister answered "Maybe, Not Sure", "No, Probably," or "No, Definitely." It equals 0 otherwise.

TABle 3

Settlement: Probit Average Marginal Effect, with Dependent Variable Equal to 1 if the Parties Settle Out of Court*

\begin{tabular}{|c|c|c|c|c|c|c|}
\hline & (1) & $(2)$ & $(3)$ & $(4)$ & $(5)$ & $(6)$ \\
\hline Winner-take-all & $\begin{array}{r}-0.25 \\
(0.15)\end{array}$ & $\begin{array}{c}-\mathbf{- 0 . 2 8} \\
(0.15)\end{array}$ & $\begin{array}{r}-\mathbf{- 0 . 4 3} \\
(0.16)\end{array}$ & $\begin{array}{l}\mathbf{- 0 . 4 7} \\
(0.17)\end{array}$ & $\begin{array}{l}\mathbf{- 0 . 4 1} \\
(0.16)\end{array}$ & $\begin{array}{c}\mathbf{- 0 . 4 6} \\
(0.17)\end{array}$ \\
\hline $\begin{array}{l}\text { Difference in Fairness } \\
\text { (pre-question } 4 \text { in } \$ 100 \mathrm{~K} \text { ) }\end{array}$ & & $\begin{array}{l}\mathbf{- 0 . 1 5} \\
(0.07)\end{array}$ & & & $\begin{array}{r}-0.08 \\
(0.08)\end{array}$ & $\begin{array}{r}-0.11 \\
(0.07)\end{array}$ \\
\hline $\begin{array}{l}\text { Difference in Undue Influence } \\
\text { (pre-question } 3 \text { ) }\end{array}$ & & & $\begin{array}{l}-\mathbf{0 . 2 2} \\
(0.09)\end{array}$ & & $\begin{array}{r}-0.17 \\
(0.1)\end{array}$ & \\
\hline $\begin{array}{l}\text { Disagree on Undue Influence: } \\
\text { ( } 0 \text { if both yes or both no on pre- } 3 \text { ) }\end{array}$ & & & & $\begin{array}{l}\mathbf{- 0 . 5 3} \\
(0.19)\end{array}$ & & $\begin{array}{l}-0.45 \\
(0.21)\end{array}$ \\
\hline Pseudo $R^{2}$ & 0.05 & 0.15 & 0.19 & 0.19 & 0.21 & 0.23 \\
\hline
\end{tabular}


Table 3 shows that accounting for overconfidence greatly increases the effect of winnertake-all. Each of the three measures of overconfidence is significant when entered individually. Since they are correlated, they lose some significance when any two of them are considered jointly. Nonetheless, the effect of winner-take-all remains fairly stable and significant. This means that, all else equal, moving from a doctrine of judicial discretion to winner-take-all will reduce the probability of an out-of-court settlement by 28 to 47 percentage points.

We find similar effects if we look at delay. Table 4 shows the results of Tobit analysis of time remaining in the bargaining period when an agreement is reached. If an agreement is never reached, the dependant variable is censored at zero. Using the same independent variables, we again see that winner-take-all causes significant delay. Combined with the results of Table 3, this provides a strong endorsement of our theory.

\section{TABLE 4}

Delay: Tobit Regressions, with Dependent Variable

Equal to the Time Remaining when Negotiators Reach an Agreement, and Equal to Zero if No Agreement is Reached.*

Winner-take-all

\begin{tabular}{cccccc}
$(1)$ & $(2)$ & $(3)$ & $(4)$ & $(5)$ & $(6)$ \\
\hline-4.15 & -4.21 & $\mathbf{- 7 . 2 0}$ & $\mathbf{- 7 . 2 1}$ & $\mathbf{- 6 . 1 0}$ & $\mathbf{- 6 . 3 7}$ \\
$(2.78)$ & $(2.32)$ & $(2.86)$ & $(2.82)$ & $(2.59)$ & $(2.47)$ \\
& & & & & \\
& $\mathbf{- 3 . 3 3}$ & & & $\mathbf{- 2 . 2 6}$ & $\mathbf{- 2 . 4 3}$ \\
& $(1.06)$ & & & $(1.09)$ & $(.97)$
\end{tabular}

(pre-question 4 in $\$ 100 \mathrm{~K}$ )

(1.06)

Difference in Undue Influence

$-3.82$

(pre-question 3)

Disagree on Undue Influence:

$-8.72$

$-6.01$

(0 if both yes or both no on pre-3)

(2.84)

\begin{tabular}{lrrrrrr} 
Constant & -0.60 & $\mathbf{6 . 4 5}$ & $\mathbf{5 . 7 2}$ & $\mathbf{7 . 1 2}$ & $\mathbf{8 . 1 4}$ & $\mathbf{9 . 3 3}$ \\
& $(1.91)$ & $(2.33)$ & $(2.35)$ & $(2.64)$ & $(2.42)$ & $(2.60)$ \\
Pseudo $R^{2}$ & 0.02 & 0.10 & 0.09 & 0.10 & 0.13 & 0.14 \\
\hline
\end{tabular}

${ }^{*}$ Bold is significant at 0.05 level. Italic is significant at 0.10 level 


\section{Summary and Conclusions}

Institutional rules for resolving disputes can have costly unintended consequences. We illustrate this with judicial doctrine of winner-take-all as compared to judicial discretion. Our theoretical models showed that winner-take-all magnifies the effects of overconfidence by concentrating all of the bias at the most extreme outcome of "winning it all," and thereby undermines chances for pre-trial negotiations to reach agreement. This model can explain the empirical observation that will contests end up in court at far greater rates than other litigation. We use a laboratory experiment to confirm our claims, and find evidence of both overconfidence among bargainers and greater disagreement under winner-take-all.

This finding is particularly remarkable given the likely role of risk aversion. Since winnertake-all redistributes the possible court outcomes to the tails of the distribution, it increases risk (Rothschild and Stiglitz, 1970). This would mean that risk averse bargainers should be more likely to settle under winner-take-all. Risk aversion, therefore, works in the opposite direction of overconfidence, making both the empirical finding about will contests and our experimental finding all the more powerful.

We see at least three other areas where winner-take-all rules may be contributing to disagreements in bargaining. First is the general area of laws about property, including disputes on real estate boundaries, abandoned property, or squatters' rights. These cases, like will disputes, are often decided on a winner-take-all basis and, therefore, may discourage settlement by the parties involved.

A second and particularly timely application of this issue is to patent rights. Prior to 2006, it was generally understood that the remedy for a successful patent infringement case is that the court would award an injunction prohibiting the infringer from practicing the patented invention. This rule gave the holder of the patent tremendous leverage in any subsequent negotiation with the infringer of the patent, and essentially constituted a winnertake-all system in that if patent infringement was found, then the holder of the patent would get "everything" and if there was no infringement of a patent then the alleged patent holder 
would get nothing. The Supreme Court recently moved away from this all-or-nothing rule in eBay, Inc. v. MercExchange, LLC, 126 S. Ct. 1837, 1840-41 (2006), a case involving the popular web-auction site eBay and patent rights to the "buy now" button used on the website. The Court gave greater discretion to judges by rejecting the prior rule that a finding of patent infringement automatically warranted an injunction. ${ }^{15}$. This decision gives judges greater discretion in awarding remedies in patent disputes and, based on our findings, should result in more negotiated settlements between the parties.

A third application is to private contracts that include fixed penalties for breach, called "liquidated damages." If courts were to consistently uphold liquidated damages claims, this would create a winner-take-all system which could impede settlement of recontracting disputes, resulting in lower efficiency. However, courts have not taken this approach with liquidated damages provisions. Although courts quite often cite the general provision that, under the fundamental principle of freedom of contracts, parties have a broad right to stipulate damages in the event of breach, in fact a variety of circumstances in which courts will refuse to enforce the liquidated damages provision bind on public policy grounds. ${ }^{16}$ Under our theory, this overlay of judicial discretion should encourage settlement by parties.

What do our results tell us about optimal institutional design? If efficiency is an important concern for the courts, this analysis may indicate that judicial doctrines that allow judges or juries discretion will be more socially desirable. As our theoretical analysis shows and our experimental evidence confirms, the judicial doctrine of winner-take-all, while socially benign with unbiased litigants, can have unintended negative consequences in the more realistic situation that litigants are overconfident.

\footnotetext{
${ }^{15}$ Rather, in order to get an injunction, the holder of the patent must, in addition, show that the traditional four part test for injunctive relief has been met.

${ }^{16}$ See the Williston on Contracts Database updated May 2007, Richard A. Lord, Chapter 65, Liquidated Damages and Penalties I. Introduction $\S 65: 1$, Validity of provisions for liquidated damages, generally.
} 


\section{Appendix}

\section{Contents of the Appendix:}

1. Subjects' Instructions

2. Sample Negotiation Chatroom Screen

3. Fact Pattern for Person A

4. Fact Pattern for Person B

5. Manipulations for Fact Patterns

6. Pre-negotiation Questionnaire

7. Sample Transcript: Judicial Discretion, Agreement (highlights added)

8. Sample Transcript: Winner-take-all, Disagreement (highlights added) 


\section{SUBJECTS’ INSTRUCTIONS}

\section{Welcome}

Welcome and thank you for participating. Just for agreeing to participate today we will start you off with $\$ 12$. The amount that you will ultimately be paid today will be between $\$ 11.70$ and $\$ 24$, and will depend in part on the judgments of you and the other participants in today's study.

\section{Instructions}

This study concerns a legal dispute involving a person who has recently died. The facts you will read are based on a real life situation. The dispute involves $\$ 400,000$. There are two people who have competing claims to this money, and they disagree about how much each person deserves to inherit.

In this study, we are going to ask you to assume the identity and legal rights of one of the people involved in this dispute. Your task in the experiment is to evaluate your legal position (as laid out in the fact pattern) and then to resolve the dispute, either by settling with the other person or by "going to court" and getting the amount awarded by the judge.

Part of this study will involve your assessment of what you think a judge is likely to decide in this case. To aid you in this decision, we will give you a statement of the applicable law.

\section{Your Award}

The amount of money you earn in this experiment will be based on two factors: (1) your share of the inheritance, and (2) any legal fees that you incur.

Your Share of the Inheritance: We will pay you $\$ 3$ for each $\$ 100,000$ of the estate that you inherit-- either as awarded by the judge or as negotiated in the out of court settlement. For example, if you inherit $\$ 300,000$, we will pay you $\$ 9$. If you inherit $\$ 110,000$ then we will pay you $\$ 3.30$. These amounts are in addition to the $\$ 12$ participation fee that we will give you for participating in today's experiment.

- If you decide to go to court, the amount that you inherit will be the amount awarded by the judge. Prior to this experiment, we had a real probate judge render a decision in this case based on the law described in the case. That decision is in a sealed envelope.

- If you reach a negotiated settlement, the amount that you inherit will be the amount that you agree to with the other party to the dispute. 
Reduction for Legal Fees: If you choose to go to court (or if you do not reach a negotiated settlement), you will need to pay the legal fees and your award will be reduced by $\$ 0.30$ to reflect $\$ 10,000$ of additional legal costs associated with going to court. Thus, if you are awarded $\$ 350,000$ by a court, you will receive $\$ 10.50$ plus your $\$ 12$ participation fee minus a $\$ 0.30$ court fee, for a total amount of $\$ 22.20$. In some cases this can result in you receiving less than your full $\$ 12$ participation fee. For example, if you decide to go to court and a court awards you $\$ 0$, you will receive your $\$ 12$ participation fee minus a $\$ 0.30$ court fee, for a total amount of $\$ 11.70$. If you reach a negotiated settlement, you do not need to pay legal fees.

\section{How You Discuss an Out of Court Settlement}

Your task is to decide whether to let the case be determined by going to court, in which case you will get the amount awarded by the judge, or to reach a negotiated settlement.

In negotiating a settlement you may appeal to anything that you believe will be persuasive in getting an agreement.

All of your discussions for an out-of-court settlement will be conducted over the computer. The person assuming the role of the other possible heir to the estate is another person in the study today. However, we will never reveal the identity of this other person to you, nor will we reveal your identity to the other person. Moreover, the experimenters will never record your name anywhere. Your identity and decisions are kept perfectly private. For this reason, please do not reveal any personal information about yourself, such as your name or what you look like, that would help the other person in the experiment identify you. Also, please do not ask the other person to reveal something that could identify him or her.

You will communicate with the other person using a computer. This screen allows conversation in a "chat room" format. The top box records the messages sent between you and the other person. Below this is a text box where you can enter your message.

The box at the bottom can be used to send a proposed settlement, or to accept a proposal made by the other person. You can send a proposed settlement to the other person by filling in the form called Send a Proposal and clicking SEND PROPOSAL. The most recently proposed settlement is shown in the box below this. If the other person has proposed a settlement that you want to accept, click the button labeled ACCEPT PROPOSAL.

Important: Discussions end when one of the two people accepts a proposal made by the other person. We will use this agreement as the basis for your earnings today.

You will have 15 minutes to discuss the case and agree upon a proposal before the case goes to court. The clock at the top of the screen that will count down the time until the 
case goes to court. If the case goes to court, we will use the judge's ruling to determine your earnings for the study.

Note, we will wait the full 15 minutes before we begin to calculate and prepare your monetary payoffs. Hence, even if you and the other person reach an agreement before this time, you must wait the full 15 minutes before you can receive your earnings and leave.

\section{Case Materials}

Your case materials are in the envelope at your desk. Please read and study the case materials carefully. Try your best to imagine yourself in the role of the person in this case. You may assume this person's identity during your discussions for a settlement.

We will give you 15 minutes to read the materials and prepare your thoughts before we begin out-of-court discussions.

Thank you and good luck! 
You are Person B logged in with $\mathrm{D} 0$

Time Remaining: 19:52

Discussion Transcript

Type your message below, then hit the Send button or the Enter key.

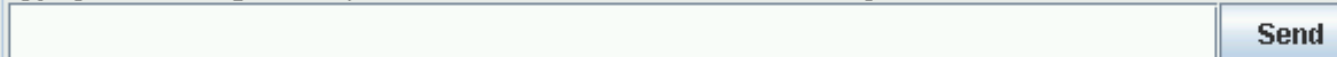

Send a Proposal

I propose \$

for me and \$

for the other person.

Remember:

- Valid entries are between and including 0 to 400000 and are multiples of 100

- If you update one value hit the Enter key to automatically update the other.

Send Proposal

No proposal proposed as of yet 


\section{FACT PATTERN A}

You are a 46 year old man. Your father died eight years ago and your mother died this year at the age of 78. Your mother's will provides that her estate is to be divided evenly between you and your sister. However, you recently learned that three months before her death, your mother transferred a bank account with a large amount of money, $\$ 800,000$, to your sister, effectively cutting you out from sharing in that account under your mother's will. If your mother had not made this transfer, you would have inherited $\$ 400,000$ from this account (that is, $50 \%$ of the $\$ 800,000$ ), and your sister would have inherited $\$ 400,000$. Instead you inherited nothing from this account.

You are a lawyer. You used to live near your parents' home, but five years ago you accepted a job in Washington, D.C. This job has been great for your career, but due to the demanding nature of the work, it kept you from being able to visit your mother as much as you would have liked. Nonetheless, you were always a devoted son; you called often and visited when you could.

Your sister is a single mother of a 10 year old girl. She is an artist and has not been able to support herself and her daughter through her work. Two years ago your sister moved back into the family home to live with your mother. At first you were happy about this as it seemed to provide a mutually beneficial situation for both your mother and sister: your sister and niece lived rent-free, while your mother had close companionship. However, in recent years you became concerned. As your mother showed signs of aging (she was often confused and increasingly dependent on your sister to make even the simplest decisions for her), you became apprehensive that your sister seemed to be controlling your mother both financially and emotionally. Moreover, you suspect that your sister worked to turn your mother against you. Several times when you called your mother, your sister answered the phone and refused to put you through (claiming your mother was napping). Your sister didn’t even tell you when your mother was hospitalized in the months prior to her death.

All of your fears were confirmed when you learned of the transfer of the bank account. It's not just the money that bothers you, it is the principle of the thing: your mother clearly wanted you and your sister to share her estate equally and you feel it is important to uphold your mother's wishes.

You consulted a lawyer who told you that you could challenge the transfer based on the legal doctrine of undue influence. The lawyer explained to you that undue influence is more than just influence or persuasion. Rather, it is influence so extreme that it causes the person to do something that is contrary to her true wishes. In other words, the issue for the court in an undue influence case is whether the transfer reflected your mother's true wishes or whether it was the product of overreaching by your sister. Your lawyer is very experienced and he told you that he believes you have a strong case. 
Your lawyer told you that unless you and your sister reach an out of court settlement on how to divide the disputed $\$ 400,000$, the judge will make a decision as to the allocation of the disputed money.

If the judge finds that the transfer was the product of undue influence, then you will receive the entire $\$ 400,000$ in dispute and your sister will receive nothing. If the judge finds that the transfer was not the product of undue influence, then you will receive nothing, and your sister will receive the $\$ 400,000$ in dispute.

Your lawyer also advised you that it will cost $\$ 10,000$ to litigate the case in court in the event that you do not reach a negotiated agreement. 


\section{FACT PATTERN B}

You are a 43 year old woman. You are a freelance commercial artist and a single mother of a 10 year old girl. Your father died eight years ago. Two years ago you moved from New York City (where your career had just begun to take off) back to your parents' home so that your mother would not be alone. Over the past two years you spent much of your time devoted to your mother's care. You made sure she took her medicines, drove her to her appointments and helped her pay her bills and manage her finances. Over the past year these tasks took up more and more time as your mother showed signs of aging - she was often confused and increasingly depended on you to make decisions for her. Between taking care of your mother and your daughter you had little time left to focus on your career. Nonetheless, you felt like you had made the right choices. You were deeply saddened when your mother died this past year at the age of 78 .

You have a brother who is three years older than you who is a very successful lawyer working in Washington, D.C. You and your brother have always been very different types of people and never particularly close, although prior to recent events, there has never been any animosity between you.

Three months before your mother died, you drove her to her bank so that she could change her bank account to provide that you would get the money in the account, $\$ 800,000$, at the time of her death, rather than having it pass through her estate to you and your brother. If your mother had not made this transfer, you would have inherited $\$ 400,000$ from this account (that is, $50 \%$ of the $\$ 800,000$ ) and your brother would also have inherited $\$ 400,000$. Instead your brother inherited nothing from this account.

You were glad that your mother finally saw things your way. After all, you were the one with the difficult financial situation as well as the only one with a child (not to mention the one who had sacrificed a career to take care of her). Moreover, your brother neither needed nor deserved the money. As you told your mother, he has been far from devoted. He didn’t even come see her when she was in the hospital.

Your brother is very well-off financially and has no dependants. Moreover, he is well aware of how much you and your daughter have been struggling financially since you moved back home. He should be incredibly appreciative for everything that you did for your mother. Therefore, you were completely taken aback when your brother told you that he had consulted a lawyer and was planning to challenge the gift based on undue influence. It's not just the money that bothers you, it is the principle of the thing: your mother clearly wanted you and your daughter to have this money and you feel it is important to uphold your mother's wishes.

You consulted a lawyer who explained to you that undue influence is more than just influence or persuasion. Rather, it is influence so extreme that it overrides the person's free agency and causes her to do something that is contrary to her true wishes. In other words, the issue for the court in an undue influence case is whether the gift by 
your mother of the bank account reflected your mother's true wishes or whether it was the product of overreaching by you. You were hurt and angry when you realized what your brother was accusing you of, and thought it was particularly outrageous in light of the fact that your brother had been focusing on his career while you devoted yourself to your mother's care. Your lawyer is very experienced and he told you that you he believes you have a strong case.

Your lawyer told you that unless you and your brother reach an out of court settlement on how to divide the disputed $\$ 400,000$, the judge will make a decision as to the allocation of the disputed money.

If the judge finds that the transfer was not the product of undue influence, then you will receive the entire $\$ 400,000$ in dispute and your brother will receive nothing. If the judge finds that the transfer was the product of undue influence, then you will receive nothing, and your brother will receive the $\$ 400,000$ in dispute.

The lawyer also advised you that it will cost $\$ 10,000$ to litigate the case in court in the event that you do not reach a negotiated agreement. 


\section{MANIPULATIONS:}

For 1)

A:

If the judge finds that the transfer was the product of undue influence, then you will receive the entire $\$ 400,000$ in dispute and your sister will receive nothing. If the judge finds that the transfer was not the product of undue influence, then you will receive nothing, and your sister will receive the $\$ 400,000$ in dispute.

B:

If the judge finds that the transfer was not the product of undue influence, then you will receive the entire $\$ 400,000$ in dispute and your brother will receive nothing. If the judge finds that the transfer was the product of undue influence, then you will receive nothing, and your brother will receive the $\$ 400,000$ in dispute.

For 2)

For both A and B:

The judge will consider all of the facts and circumstances and will make a fair and equitable distribution of the $\$ 400,000$ in dispute. This will result in you being paid somewhere between $\$ 0$ and $\$ 400,000$. 
Participant Number

\section{Pre-Negotiation Questionnaire}

After reading the facts of the case, but before you negotiate, please answer the following questions:

1. If the case goes to court, what is your best guess of the judge's decision?

[Alternative i: ]

Check one:

_ The transfer of the bank account is upheld and the daughter gets the disputed $\$ 400,000$ and the son gets nothing.

_ The transfer of the bank account is rejected and the son gets the disputed $\$ 400,000$ and the daughter gets nothing.

[Alternative ii: ]

Fill in amounts that sum to $\$ 400,000$

Amount to the son

Amount to the daughter

2. How much confidence do you have in your answer to the question above?

_ great deal of confidence _ only some confidence _ _ hardly any confidence

3. Do you think the daughter exerted "undue influence" on her mother's decision to transfer the bank account three months before her death?

_ Yes, definitely.

Yes, probably.

Maybe, not sure

No, probably.

No, definitely.

4. What do you consider is a fair division of the disputed $\$ 400,000$ in this case?

(Fill in amounts that sum to $\$ 400,000$ )

Amount to the son

Amount to the daughter 


\title{
Sample Transcript 1: Judicial Discretion, Agreement
}

\author{
Group 5 \\ Player A: 2 \\ Player B: 9
}

(14:53 remaining) Person B: hey bro

(14:49 remaining) Person A: hello

(14:44 remaining) Person A: where do we start?

(14:31 remaining) Person B: so you think i conned mother into giving me all the money?

(14:17 remaining) Person A: do you see any possible settlement before court or not a chance?

(14:05 remaining) Person A: it certainly would appear that way

(14:02 remaining) Person B: possibly

(13:54 remaining) Person B: i also see a settlement here too

(13:39 remaining) Person B: how much you think you deserve?

(13:11 remaining) Person A: ultimately i feel it is justified to recieve the 400,000 because that was the original half of the account

(13:00 remaining) Person A: i realize that will not happen otherwise we wouldnt be here (12:26 remaining) Person B: however, i was the one who has cared for her every need for the past 2 years

(12:19 remaining) Person B: i gave up my career for her

(11:59 remaining) Person B: i gave up any chance to make a decent living

(11:55 remaining) Person B: all for her

(11:47 remaining) Person A: what distinguishes you giving up your career to help vs

having no career and depending on her

(11:28 remaining) Person B: so i think i t is completely justified to think that i deserve at least more than half of the inheritance

(11:27 remaining) Person A: your choice to be an artist was one made many years prior to moving in with mother

(11:17 remaining) Person A: i would agree with that statement

(11:02 remaining) Person A: i am willing to give you more than half since i know what you have given up for her

(10:48 remaining) Person A: would you consider a percentage split?

(10:40 remaining) Person B: 25:75

(10:27 remaining) Person B: i mean, you 25, me 75

(10:27 remaining) Person A: 25 extra to you and 75 of the 400000 to me?

(9:42 remaining) Person B: not only will it go towrds supporting me, but my daughter also

(9:40 remaining) Person A: as in you get 700000 and i get 100000

(9:33 remaining) Person B: yes

(8:57 remaining) Person B: seem fair to you?

(8:56 remaining) Person A: just because your lifestyle is one that includes a dependant does not change the amount that you should get

(8:45 remaining) Person A: me being single should not punish me 
(8:16 remaining) Person B: i understand that, but my daughter was also helpoed out immesnsely with taking care of mother (8:10 remaining) Person B: it wasnt solely me

(8:01 remaining) Person B: she had to make many sacrafices to

(7:59 remaining) Person B: o

(7:59 remaining) Person A: $\mathrm{i}$ was thinking more along the lines of 60/40 since you will be residing at her house now that it is empty, you also inherited the house

(7:22 remaining) Person A: she is not legally an adult nor was she included in the will, therefor the judge will not view her in the decision

(6:45 remaining) Person B: you are very well of as it is, and you dont need the monay as nearly as much as i can use it

(6:04 remaining) Person B: you probably cant even use all of it, without wasting it away (5:57 remaining) Person A: that will not be a deterant in court, regardless of you needing the money more, it is who is entitled to it under the law that matters (5:48 remaining) Person B: i understand that (5:12 remaining) Person A: so i am most certain that i can earn more than 100000 if we would go to court, and $\mathrm{i}$ am more than willing to pay lawyer fees

(4:45 remaining) Person B: so how much are you proposing at the current moment (3:13 remaining) Person A: 65me/35 you which is an extra 140000 for you, or a total of 540000 to my 260000

(3:04 remaining) Person A: so youre still coming out with 2 times what i have

(2:51 remaining) Person B: fair deal

(2:40 remaining) Person A: you agree to that

(2:38 remaining) Person B: i do

(2:23 remaining) Person A proposed \$260000 for themselves and \$140000 for their partner.

(2:09 remaining) Person B accepts the offer. 


\section{Sample Transcript 2: Winner-take-all, Disagreement}

Group 2

Player A: 12

Player B: 3

(14:02 remaining) Person A: would you like to settle

(13:44 remaining) Person $B$ : what is it that you suggest?

(13:08 remaining) Person A: i feel that since you were with mother last, $i$ would like to

know how you feel

(11:40 remaining) Person A: with all due respect, you should do what's in your heart

(10:55 remaining) Person B: I spent the last two years putting my career on hold in order to care for her. I uprooted my daughter from her original home in order for her to get to know our mother before she past. I acted as mother's taxi, nurse, and took care of her bills. Since i am in a finacail pinch I believe that this is a type of payment for the acts that I have done for her.

(10:35 remaining) Person B: Also it is not like you will not recieve any of the estate

(10:25 remaining) Person B: the rest we will split 5050.

(10:12 remaining) Person B: therefore i feel entitled to the whole amount.

(10:03 remaining) Person B: it was mother's wish

(9:33 remaining) Person B proposed $\$ 400000$ for themselves and $\$ 0$ for their partner.

(9:18 remaining) Person A: you have quite the argument, but on the other hand, why did you treat me the way you did when I tried to get in contact with mother?

(9:03 remaining) Person B: can you elaborate?

(7:03 remaining) Person A: when i called the house, everytime i would call, you would pick up the phone and claim mother was sleeping. I was a good son and it was like i was being blocked from communication from my own mother, besides, her will clearly stated that $\$ 200,000$ goes to me and $\$ 200,000$ goes to you

(6:35 remaining) Person A: mothers final wishes should be carried out by us splitting it in half

(6:21 remaining) Person $A$ : that is the rightous thing to do

(6:06 remaining) Person A: im sure you feel the same way

(5:26 remaining) Person A: your proposal seems a bit unfair, don't you think. i truly feel you should reconsider

(4:18 remaining) Person B: unfortunately whenever you called mother was sleeping. I regret that you feel that you were being blocked. That was never my entention. However, I would like to point out that dad died eight years ago. Mother has been very sick for a little over two. You have not come home one time. I understand that you are very busy with you career, yet no matter what has happened between you and me you could have come home to see Mother during the last few years of her life.

(4:02 remaining) Person B: You have not been in communication with mother for some time now

(3:56 remaining) Person B: people change there minds.

(3:38 remaining) Person B: during thelast few years, mother changed her mind about the 
inheritance

(3:05 remaining) Person A: yes people change their minds, but when other people change their minds for them, it loses it validity

(2:45 remaining) Person B: i'm sorry you feel that way

(2:35 remaining) Person A: mother did not officially change her mind about the

inheritance

(2:32 remaining) Person $B$ : is there a settlement you would like to suggest?

(2:19 remaining) Person B: yes she did.

(2:09 remaining) Person $B$ : she was the one at the bank doing the transactions

(2:01 remaining) Person B: i did not

(1:32 remaining) Person A: im not gonna argue with you, that childish, it hurts me to hear you say that you feel you deserve everything (keeping in mind your proposal)

(1:02 remaining) Person B proposed $\$ 300000$ for themselves and $\$ 100000$ for their partner.

(0:48 remaining) Person A: why the hell didn't you tell me mother was in the hospital (0:28 remaining) Person A: let split it 200000 for me and 200000 for $\mathrm{u}$

(0:18 remaining) Person A proposed \$200000 for themselves and \$200000 for their partner. 


\section{References}

Ashenfelter, Orley, Currie, Janet, Farber, Henry S., and Spiegel, Matthew, "An Experimental Comparison of Dispute Rates in Alternative Arbitration Systems." Econometrica, 1992, 60, Nov., 1407-1433.

Ausubel, Lawrence M.; Cramton, Peter; and Deneckere, Raymond J., "Bargaining with Incomplete Information." in R.J. Aumann and S. Hart, eds., Handbook of Game Theory, Volume 3, Chapter 50, Amsterdam:Elsevier, 2002.

Babcock, Linda; Loewenstein, George; Issacharoff, Samuel and Camerer, Colin. "Biased Judgements of Fairness in Bargaining." The American Economic Review, 1995, 85(5). 1337-43.

Babcock, Linda; Loewenstein, George, and Wang, Xianghong. "The Relationship Between Uncertainty, the Contract zone, and Efficiency in a Bargaining Experiment." Journal of Economic Behavior and Organization, 1995, 27, 475-85.

Babcock, Linda and Loewenstein, George. "Explaining Bargaining Impasse: The Role of SelfServing Biases." Journal of Economic Perspectives, 1997, 11(1), 109-26.

Babcock, Linda; Wang, Xianghong and Loewenstein, George. "Choosing the Wrong Pond: Social Comparisons in Negotiations That Reflect a Self-serving Bias." The Quarterly Journal of Economics, 1996, 91(1), 1-19.

Crawford, Vincent P., "On Compulsory Arbitration Schemes." Journal of Political Economy, $1979,87,131-160$.

Crawford, Vincent P., "Arbitration and Conflict Resolution in Labor-Management Bargaining." American Economic Review, P\&SP, 1981, 71, 205-210.

Dickinson, D.L., “A Comparison of Conventional, Final-offer, and 'Combined' Arbitration for Dispute Resolution." Industrial and Labor Relations Review, 2004, 57 (2), 288-301.

Dickinson, D.L., "The Chilling Effect of Optimism: The Case of Final-offer Arbitration." The Journal of Socio-Economics, 2006, 35, 17-30. 
De Waal, Marius J. "Comparative Succession Law." in Mathias Reimann and Reinhard Zimmerman, eds. The Oxford Handbook of Comparative Law, 2006, 1085.

Farber, H.S. "An Analysis of Final-Offer Arbitration." Journal of Conflict Resolution, 1980, 24, 683-705.

Farber H.S. and Bazerman, M.H. , "The General Basis of Arbitrator Behavior: An Empirical Analysis of Conventional and Final-Offer Arbitration." Econometrica, 1986, 24, 1503-1528.

Landes, William M. "An Economic Analysis of the Courts." Journal of Law and Economics, $1971,14(1), 61-107$.

Neale, M.A, and Bazerman, M.H., "The Role of Perspective Taking Ability in Negotiating Under Different Forms of Arbitration." Industrial and Labor Relations Reciew, 1983, 36, 378-388.

Madoff, Ray D. "Lurking in the Shadow: The Unseen Hand of Doctrine in Dispute Resolution." Southern California Law Review, 2002, 76, 161-187.

Madoff, Ray D., Cornelia R. Tenney, and Martin A. Hall, Practical Guide to Estate Planning, 2008, CCH Inc.

Myerson, R.B., and M.A. Satterthwaite "Efficient Mechanisms for Bilateral Trading." Journal of Economic Theory, 1983, 28, 265-281.

Olszewski, Wojciech, "A Welfare Analysis of Arbitration.” working paper, Northwestern University, June, 2006.

Posner, Richard. "The Behavior of Administrative Agencies." Journal of Legal Studies, 1972, 1,305 .

Rothschild, Michael and Stiglitz, Joseph E. "Increasing Risk I: A Definition." Journal of Economic Theory, 1970, 2, 225-243.

Schoenblum, Jeffrey A. "Will Contests-An Empirical Study." Real Prop., Prob. E Tr. Journal 1987, 22, 607-14. 
Trubek, David; Sarat, Austin; Felstiner, William L.F.; Kritzer, Herbert M. and Grossman, Joel B. "The Costs of Ordinary Litigation." UCLA Law Review, 1983, 31, 72-89.

Yildiz, Muhamet. "Bargaining Without a Common Prior-An Immediate Agreement Theorem." Econometrica, 2003, 71(3), 793-811.

Yildiz, Muhamet. "Waiting to Persuade." The Quarterly Journal of Economics, 2004, 223-48. 